\title{
Correction to: Growth mechanism identification of sputtered single crystalline bismuth nanowire
}

\author{
Haiyang Hong ${ }^{1} \cdot$ Lu Zhang $^{1} \cdot$ Chunyu Yu ${ }^{1} \cdot$ Ziqi Zhang $^{1}$. Cheng $\mathrm{Li}^{1}$ - Songyan Chen ${ }^{1}$. Wei Huang ${ }^{1}$ Jianyuan Wang ${ }^{1}$. \\ Jianfang $\mathrm{Xu}^{1}$
}

Published online: 22 May 2019

(c) King Abdulaziz City for Science and Technology 2019

\section{Correction to: Applied Nanoscience \\ https://doi.org/10.1007/s13204-019-01026-0}

The article listed above was initially published with incorrect copyright information. Upon publication of this correction, the copyright of the article is changed to "King Abdulaziz City for Science and Technology".

The original article has been corrected.

Publisher's Note Springer Nature remains neutral with regard to jurisdictional claims in published maps and institutional affiliations.

The original article can be found online at https://doi.org/10.1007/ s13204-019-01026-0.

\section{Cheng Li}

lich@xmu.edu.cn

1 Semiconductor Photonics Research Center, OSED, Department of Physics, Jiujiang Research Institute, Xiamen University, Xiamen 361005, Fujian, People's Republic of China 